\title{
U-RANS SIMULATIONS AND PIV MESUREMENTS OF A SELF-EXCITED CAVITATION VORTEX ROPE IN A FRANCIS TURBINE
}

\author{
Jean, Decaix ${ }^{1}$ \\ Mailing address \\ jean.decaix@hevs.ch \\ Andres, Müller \\ Mailing address \\ andres.mueller@epfl.ch \\ Arthur, Favrel \\ Mailing address \\ arthur.favrel@epfl.ch \\ François, Avellan \\ Mailing address \\ Francois.Avellan@epfl.ch \\ Cécile, Münch \\ Mailing address \\ cecile.muench@hevs.ch
}

\section{KEY WORDS}

Homogeneous model, unsteady analysis, ANSYS CFX.

\begin{abstract}
In the course of the massive penetration of alternative renewable energies, the stabilization of the electrical power network significantly relies on the off-design operation of turbines and pump-turbines in hydropower plants. The occurrence of cavitation is however a common phenomenon at such operating conditions, often leading to critical flow instabilities, which undercut the grid stabilizing capacity of the power plant. In order to predict and extend the stable operating range of hydraulic machines, a better understanding of the cavitating flows and mainly of the transition between stable and unstable flow regimes is required. In the case of Francis turbines operating at full load, an axisymmetric cavitating vortex rope develops at the outlet runner in the draft tube. The cavity may enter self-oscillation, with violent periodic pressure pulsations propagating throughout the entire hydraulic system. The flow fluctuations lead to dangerous electrical power swings and mechanical vibrations through a fluid-structure coupling across the runner, imposing an inconvenient and costly restriction of the operating range.

The paper deals with a numerical and experimental investigation of the transition from a stable to an unstable operating point on a reduced scale model of a Francis turbine at full load. Unsteady homogeneous two-phase RANS simulations are carried out using the ANSYS CFX solver. Cavitation is modelled using the Zwart's model that required solving an additional transport equation for the void fraction. Turbulence is solved using the SST $k-\omega$ model. Simulations are compared with the experimental measurements and some insights are provided for a first comprehensive analysis of the transition between the stable and unstable states.
\end{abstract}

\section{INTRODUCTION}

The rapidly growing share of new and renewable energy sources in the past decades lead to new challenges for the electrical network stability. Due to their rapid response time, hydraulic power plants are often used to

\footnotetext{
${ }^{1}$ Corresponding author
} 
compensate load fluctuations in the grid. The injection of the suitable amount of power however requires the hydraulic machines to run outside of their Best Efficiency Point (BEP) for which they were designed. As a consequence, the flow leaving the runner possesses a significant residual swirl, leading to an inhomogeneous pressure distribution in the draft tube and eventually to the inception of cavitation. In Francis turbines operating at partial load, this is manifested in the formation of a helical, precessing vortex rope, which was extensively investigated for the present reduced scale model by Favrel et al. [1,2]. At full load, when more discharge is passing through the machine than at the BEP, the cavitation vortex rope takes an axisymmetric shape, featuring one or several nodes, and a diameter depending on the pressure level in the draft tube. If the pressure decreases below a critical value, the cavitation vortex rope enters self-oscillation at one of the hydro-acoustic eigenfrequencies of the system, described by a characteristic breathing motion of its volume and a severe amplification of the pressure fluctuations. The phenomenon is often referred to as full load pressure surge and results in dangerous power swings. The associated hydro-mechanical loads can reach dangerous levels in actual power plants [3]. The physical mechanisms by which the self-oscillation is sustained were investigated extensively. Recent results of Laser Doppler Velocimetry (LDV) measurements and high-speed visualizations in the draft tube flow show that the cyclic appearance of cavitation on the suction side of the runner blades cause the mechanical torque fluctuations by altering the hydrodynamic properties of the blades and thus the momentum transfer to the shaft [4]. The same blade cavitation also governs the breathing motion of the cavitation vortex rope through a variation of the flow swirl. The corresponding cavities on the blades start developing at stable conditions and are growing with a decreasing cavitation number, which is confirmed numerically and experimentally in other machines for similar operating conditions [5].

Several efforts have been undertaken to simulate full-load pressure surge analytically and numerically. Dörfler et al. [6] examined the stability criteria in the draft tube cone flow by unsteady 2-phase Computation Fluid Dynamic (CFD). The cavitation vortex rope volume fluctuation seems accurately captured, however the computational domain does not include the runner. Single and two-phase flow computations including a single flow passage and the complete 3D draft tube have been carried out by Flemming et al. [7]. Based on a pressure vapor iso-surface, the single-phase flow simulation yields a larger cavitation volume than the twophase flow. A 1D-3D coupled approach is proposed in [8]. The 1D model is used to provide an accurate inlet discharge for the 3D computation. The coupling approach generates a variable mass flow rate into the 3D domain compared to a constant inlet discharge. However, the comparison with on-site measurements reveals a deviation of the dynamic pressure fluctuations both in frequency and amplitude. Chirkov et al. employed also a coupled 1D-3D model, where the computational domain inside the machine is made of a single flow channel through the wicket gates and the runner as well as the entire draft tube [9-10]. The flow appears again qualitatively well captured at different scales. More recently, the key parameters of 1D hydro acoustic models were further investigated with a similar Unsteady Reynolds-Averaged Navier-Stokes (URANS) calculation as reported in [11].

The present paper pursues the aforementioned effort by comparing the CFD results with validated experimental measurements performed at a model scale. The test case, the experimental set up and the three operating points considered are described in section 2, with a specific focus on the 2-D Particle Image Velocimetry (PIV) measurements performed at two horizontal cross-sections of the draft tube cone, as well as in one vertical (meridional) cross-section, which gives an access to the velocity field in the draft tube cone even in presence of water vapor. The detailed set up of the cavitating U-RANS simulations is presented in section 3 and the results are compared with the experimental data in section 4 . The investigation of the transition between the stable and unstable flow configurations is discussed in Section 5.

\section{EXPERIMENTAL SET UP}

The test case is a 1:16 reduced scale physical model of a Francis turbine with 16 runner blades. The real prototype machine, featuring a rated power of over $444 \mathrm{MW}$ at a specific speed of $v=0.27$, experiences severe pressure surge at high load conditions. The measurements have been carried out at the model test case on the EPFL test rig PF3. The installation is operated in a closed loop configuration. The pressure in the draft tube at the runner outlet, represented by the Thoma number $\sigma$, can be lowered with a vacuum pump located over the free surface in the downstream tank.

The operating conditions for the tests and simulations are defined by a set of non-dimensional parameters, guaranteeing the hydraulic similitude between the model and the real machine according to IEC standards [12]. The load corresponds to $130 \%$ of the value at the BEP, expressed by a discharge factor of $Q_{E D}=0.26$ 
(the discharge factor at the BEP of the machine is $Q_{E D}=0.2$ ). The speed factor, essentially representing the head, is equal to the rated value of $\mathrm{n}_{\mathrm{ED}}=0.288$. The specific speed of the model runner at these conditions is $v=0.31$. Three Thoma numbers are considered for the study, defining two stable and one unstable operating point. OP1 $(\sigma=0.38)$ is characterized by atmospheric conditions in the downstream tank and by the presence of a slender, stable cavitation vortex rope in the draft tube. At OP2 $(\sigma=0.20)$, the cavitation in the vortex core has increased in diameter and the formation of a knot in the yet stable vortex rope is observed. Finally, OP3 $(\sigma=0.38)$ has the same Thoma number as the prototype machine and displays an unstable cavitating vortex rope with a characteristic, self-excited breathing motion, i.e. a periodic collapse and reformation of the cavity accompanied by large amplitude pressure fluctuations throughout the system.

The flow field is measured in two horizontal cross-sections Section 1 (S1) and Section 2 (S2) and one vertical (meridional) cross-section, section 3 (S3), of the Plexiglas draft tube cone by means of 2-D PIV. The general setup is the same as the one used for the investigation of the partial load behavior reported in [1] and is shown in

Figure 1. The streamwise locations of the two horizontal flow survey sections are defined in

Figure 2. Two flush-mounted, piezo-resistive pressure sensors are furthermore installed on the cone wall of each measurement section with a spacing of $180^{\circ}$. Average quantitties

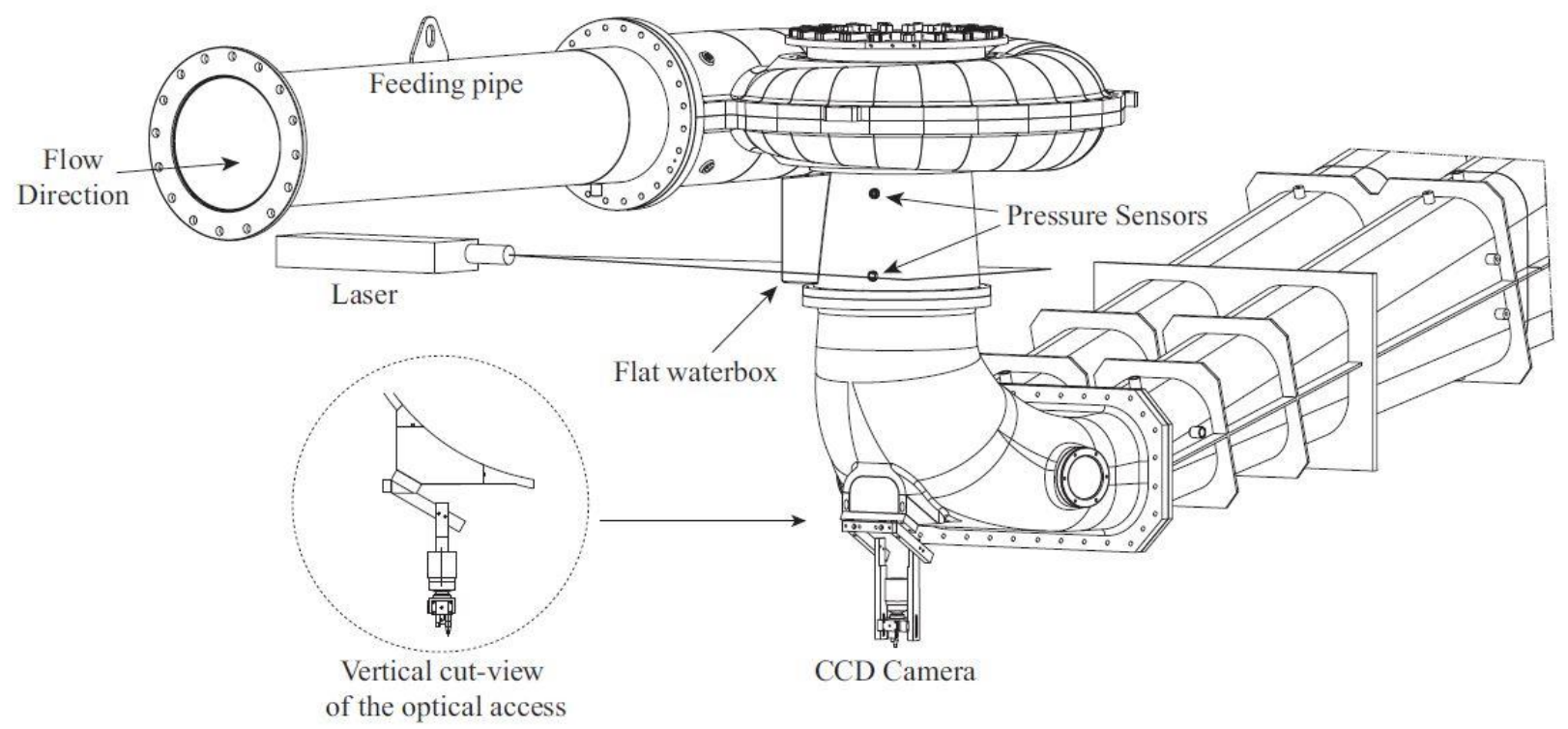

Figure 1: Flow survey instrumentation on the reduced scale model from [1].

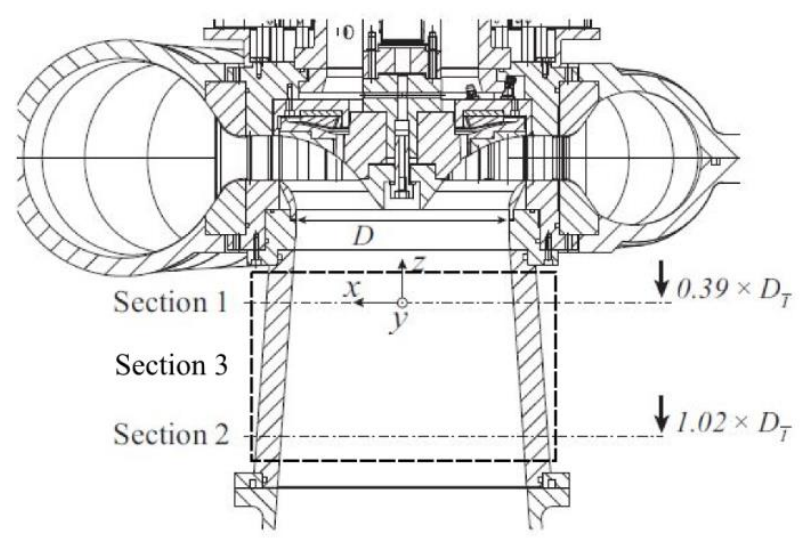

Figure 2: Horizontal and vertical (in dark grey) flow survey cross-sections (mid-plane view). 


\section{NUMERICAL SET UP}

The flow is modelled based on the homogeneous U-RANS equations [13] assuming thermodynamic and mechanical equilibrium. Therefore, the phases are assumed to share the same pressure, velocity and temperature. By neglecting the energy conservation equation, the equations to be solved are the mass conservation equation (1) and the momentum equation (2):

$$
\begin{gathered}
\frac{\partial \rho}{\partial t}+\nabla \cdot(\rho \vec{C})=0, \\
\frac{\partial \rho \vec{C}}{\partial t}+\nabla \cdot(\rho \vec{C} \otimes \vec{C})=-\nabla p+\nabla \cdot\left(\overline{\bar{\tau}}+\overline{\overline{\tau_{t}}}\right),
\end{gathered}
$$

with $\rho$ the mixture density, $\vec{C}$ the mixture velocity, $p$ the mixture pressure, $\overline{\bar{\tau}}$ and $\overline{\overline{\tau_{t}}}$ the viscous and the turbulent stresses respectively. The viscous stresses are computed assuming that the mixture is a Newtonian fluid (3):

$$
\overline{\bar{\tau}}=\mu\left(\nabla \vec{C}+\nabla^{t} \vec{C}\right)
$$

The turbulent stresses are computed using the Boussinesq's assumption (4) that introduces a turbulent viscosity $\mu_{t}$.

$$
\overline{\overline{\tau_{t}}}=\mu\left(\nabla \vec{C}+\nabla^{t} \vec{C}\right)-\frac{2}{3} \rho k \operatorname{tr}(\overline{\bar{I}})
$$

The turbulent viscosity is computed using the SST $k$ - $\omega$ model [14] that requires solving two additional conservation equations for the turbulent kinetic energy $k$ and the specific dissipation rate $\omega$.

The phase change due to cavitation is modelled by solving the mass conservation equation for the gas that writes [15]:

$$
\frac{\partial r_{g} \rho_{g}}{\partial t}+\nabla \cdot\left(r_{g} \rho_{g} \vec{C}\right)=S_{v}+S_{c}
$$

With $S_{v}$ and $S_{c}$ the terms respectively responsible for the vaporisation and the condensation processes. They are derived (see equations (6) and (7)) from the simplified Rayleigh-Plesset equation [16] that describes the dynamic behavior of a spherical bubble.

$$
\begin{gathered}
S_{v}=F_{v} \frac{3 r_{n u c}\left(1-r_{g}\right) \rho_{g}}{R_{n u c}} \sqrt{\frac{2}{3} \frac{\left|p_{v}-p\right|}{\rho_{f}}} \operatorname{sgn}\left(p_{v}-p\right) \text { if } p<p_{v}, \\
S_{c}=F_{c} \frac{3 r_{g} \rho_{g}}{R_{n u c}} \sqrt{\frac{2}{3} \frac{\left|p_{v}-p\right|}{\rho_{f}}} \operatorname{sgn}\left(p_{v}-p\right) \text { if } p>p_{v},
\end{gathered}
$$

With $F_{v}=50 ; F_{c}=0.01 ; r_{n u c}=510^{-4}$ and $R_{n u c}=10^{-6} \mathrm{~m}$ according to [17]. The saturated vapor pressure $p_{v}$ is set to $1^{\prime} 800 \mathrm{~Pa}$ (corresponding to an ambient temperature of $\mathrm{T}=16^{\circ} \mathrm{C}$ ).

The domain considered for the computation gathers the spiral case, the stay vanes, the guide vanes, the runner and the draft tube with the elbow (see

Figure 3 left). The computational domain is divided into four sub-domains: the spiral case, the stay vanes and guide vanes, the runner and the draft tube. A structured mesh (see

Figure 3 right), provided by the Institute of Fluid Mechanics and Hydraulic Machinery of the University of Stuttgart in the framework of the HYPERBOLE European research project [18], is used. The total number of nodes is of approximately 11 million.
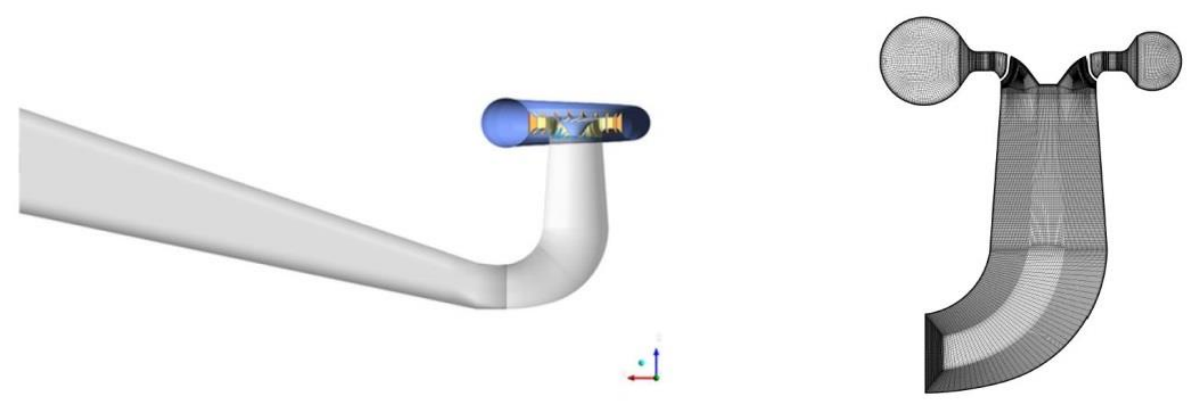
Figure 3: Computational domain (left) and view of the mesh in the x-z plane (right).

For the computations, the flow rate is imposed at the inlet, whereas the pressure is set at the outlet. For each case, the outlet pressure is adjusted to match the experimental Thoma number. A no slip condition is set at the solid walls. The average $y^{+}$value at the wall is approximately 20 and the maximum value does not exceed 60. Therefore, the turbulent stresses in the first cell layer close to a wall are computed applying a wall law. The convective fluxes in the momentum equation are computed with a high order scheme, whereas the turbulence convective fluxes are computed with an upwind scheme. Regarding the time scheme, the second order backward scheme is applied. The interfaces between stationary and rotating domains are managed using a Graphic General Interface (GGI) algorithm. For the steady computations, a stage averaging procedure is performed at the interfaces.

\section{VALIDATION OF THE CFD}

The simulations are carried out with the Ansys ${ }^{\circledR}$ CFX v15 software. Steady simulations are first run and the steady state results are used for the initialization of the unsteady simulations. For the unsteady simulations, the time step is set to $\Delta t=210^{-4}$ second, which corresponds to approximately 1 degree of revolution per time step. A physical time of $0.5 \mathrm{~s}$ is simulated for the operating point OP1 and $1 \mathrm{~s}$ for the operating point OP2, which corresponds to 13 runner revolutions. For the operating point OP3, the steady simulation converges whereas the unsteady simulation diverges.

The Thoma number cannot be computed directly from the simulation results, therefore another cavitation parameter is considered in order to verify that the same operating points are considered experimentally and numerically. The local cavitation number $\sigma_{u}$ defined by (8):

$$
\sigma_{u}=\frac{\bar{p}-p_{v}}{0.5 \rho U_{\overline{1}}^{2}}
$$

is used for the comparison. $\bar{p}$ is the mean wall pressure in the local section and $U_{\overline{1} e}$ the circumferential speed of the runner at its outlet. The cavitation number $\sigma_{u}$ in S1 and S2 located in the draft tube cone are compared between the simulations and the experiments in Table 1.The difference between the experiments and the simulations does not exceed $5 \%$.

\begin{tabular}{lll} 
Operating Point & $\boldsymbol{\sigma}_{u 1}[-]$ & $\boldsymbol{\sigma}_{u 2}[-]$ \\
\hline OP1 (RANS) & $0.87(0.86)$ & $0.92(0.90)$ \\
OP1 (U-RANS) & $0.87(0.86)$ & $0.92(0.90)$ \\
\hline OP2 (RANS) & $0.44(0.43)$ & $0.48(0.47)$ \\
OP2 (U-RANS) & $0.44(0.43)$ & $0.49(0.47)$ \\
\hline OP3 (RANS) & $0.19(0.18)$ & $0.24(0.24)$ \\
\hline
\end{tabular}

Table 1: Local cavitation number $\sigma_{u}$ in two sections of the draft tube cone. Experimental values in parenthesis.

The performances of the turbine are measured for each operating point and gathered in Table 2 for both RANS and U-RANS simulations. The head correspond to the specific energy differrence between the inlet of the spiral case and the outlet of the draft tube following the IEC standards [12]. It is noticeable that unsteady simulations (U-RANS) improve the results. For instance, the difference in head is lower than $2.5 \%$ for the URANS simulations whereas it reaches $9 \%$ for the RANS computation at OP3.

\begin{tabular}{lllll} 
Operating Point & Head $[\mathbf{m}]$ & $\mathbf{T}_{\text {ED }}[-]$ & $\mathbf{n}_{\text {ED }}[-]$ & $\mathbf{Q}_{\text {ED }}[-]$ \\
\hline OP1 (RANS) & $25.14(26.75)$ & $0.130(0.126)$ & $0.297(0.288)$ & $0.269(0.260)$ \\
OP1 (U-RANS) & $26.10(26.75)$ & $0.132(0.126)$ & $0.292(0.288)$ & $0.264(0.260)$ \\
\hline OP2 (RANS) & $25.25(26.80)$ & $0.130(0.127)$ & $0.297(0.288)$ & $0.268(0.260)$ \\
OP2 (U-RANS) & $26.33(26.80)$ & $0.131(0.127)$ & $0.291(0.288)$ & $0.263(0.260)$ \\
\hline OP3 (RANS) & $24.37(26.75)$ & $0.130(0.127)$ & $0.302(0.288)$ & $0.273(0.260)$ \\
\hline
\end{tabular}

Table 2: Turbine performances. Experimental values in parenthesis.

An iso-surface of the instantaneous liquid volume fraction $\alpha_{L}=0.9$ (see 
Figure 4) illustrates the cavitating vortex rope captured numerically. For the operating points OP1 and OP2, the vortex rope is stable as observed experimentally. At the operating point OP3, the vortex rope is unstable and cavitation occurs also at the trailing edge of the runner blades. The visualized vortex rope is shown on

Figure 5 for the three operating points. It is noticeable that the simulations under-estimate the cavitation volume of the vortex rope for each operating point most probably due to an underestimation of the pressure drop inside the vortex core. Regarding the operating point OP3, cavitation development on the runner blades is also observed experimentally $[4,19]$.

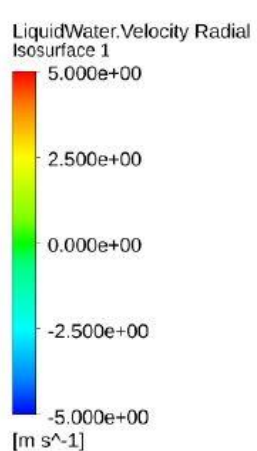

$\left[\mathrm{m} \mathrm{s} \mathrm{s}^{\wedge}-1\right]$

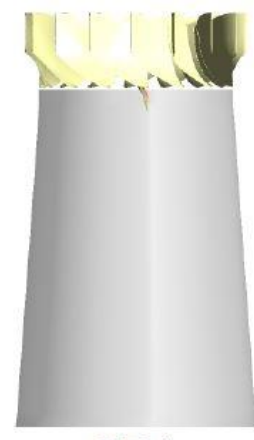

OP1

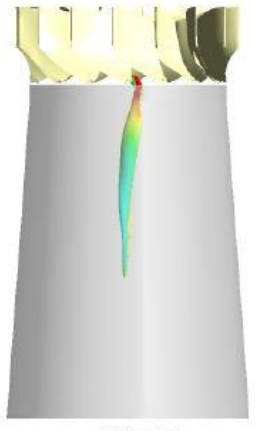

OP2

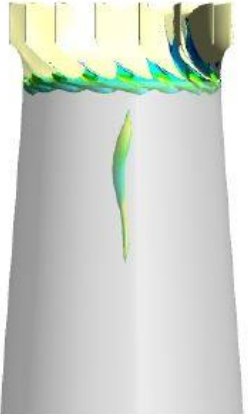

OP3

Maximum extension

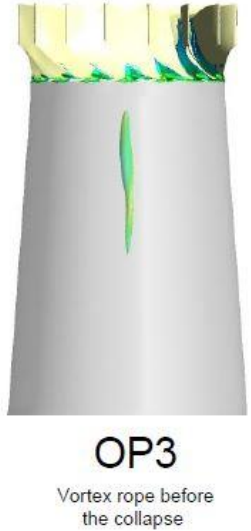

the collapse

Figure 4: Maximum extension of the cavitating vortex rope visualized with the iso-surface of the liquid volume fraction $\alpha_{L}=0.9$ colored by the radial velocity $C_{r}$. U-RANS CFD results.

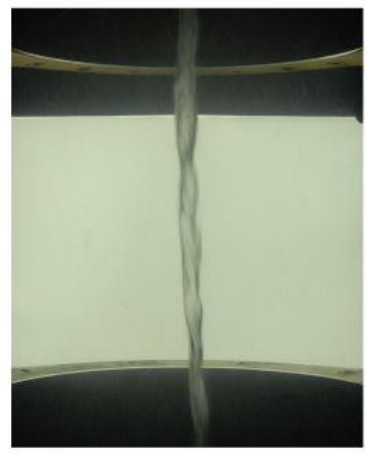

OP1

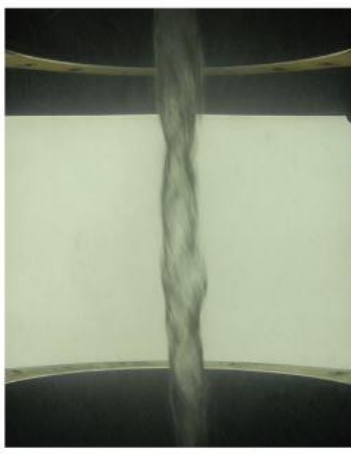

OP2

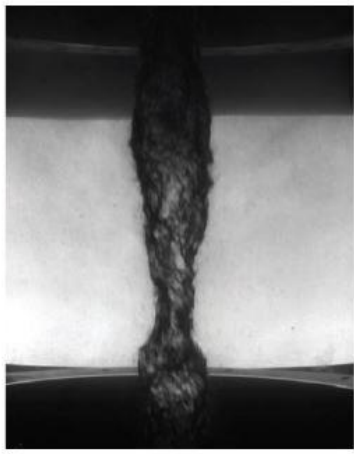

\section{OP3}

Maximum extension of the vortex rope

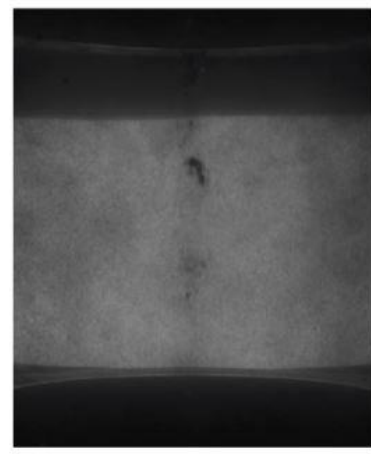

\section{OP3}

Vortex rope collapse

Figure 5: Instantaneous picture of the cavitating vortex rope. Experimental data.

The magnitude of the time-averaged cross velocity components $\sqrt{C_{u}^{2}+C_{r}^{2}}$ in horizontal sections S1 and S2 and $\sqrt{C_{Z}^{2}+C_{r}^{2}}$ in the vertical plane $\mathrm{S} 3$ are compared between CFD and measurements in Figure 6 and

Figure 7 for the operating point OP2. The experimental data are averaged over more than 200 runner revolutions whereas only 13 runner revolutions are covered by the simulation. It is however important to stress that the physical meaning of the PIV measurements inside the vortex rope and at its interface is doubtful. It cannot be quantitatively determined in what way the light sheet interacts optically with the gaseous phase and to what extend the accuracy of the cross-correlations suffers thereby. This is especially true for the horizontal measurement sections in

Figure 6, where the three-dimensional appearance of the vortex rope shape in the velocity fields suggests that many of the measurements inside and behind (below) the cavity are simply out-of-plane. For the vertical measurement sections in

Figure 7, it is the entire region inside and behind the vortex rope (to the right) which is compromised. Moreover, the limitations of the optical access through the water box are clearly illustrated by the erroneous 
cross-correlations at the top and the bottom of the same velocity fields.

In the CFD results, the influence of the vortex rope is put in evidence by the non-axisymmetric of the velocity contours marked by a highest velocity level in the region where the vortex rope imprint is observed in the measurement data. Outside of the vortex rope, the CFD results and the experimental data are in agreement showing a magnitude of the transverse velocity lower than $3 \mathrm{~m} \mathrm{~s}^{-1}$ (see the hatched portion on Figure 6). Closer to the vortex rope, the magnitude of the transverse velocity increases. Regarding the magnitude of the velocity components in the vertical section, CFD and experimental results show the same pattern with a peak velocity magnitude close to $9 \mathrm{~m} \mathrm{~s}^{-1}$ inside the vortex rope.
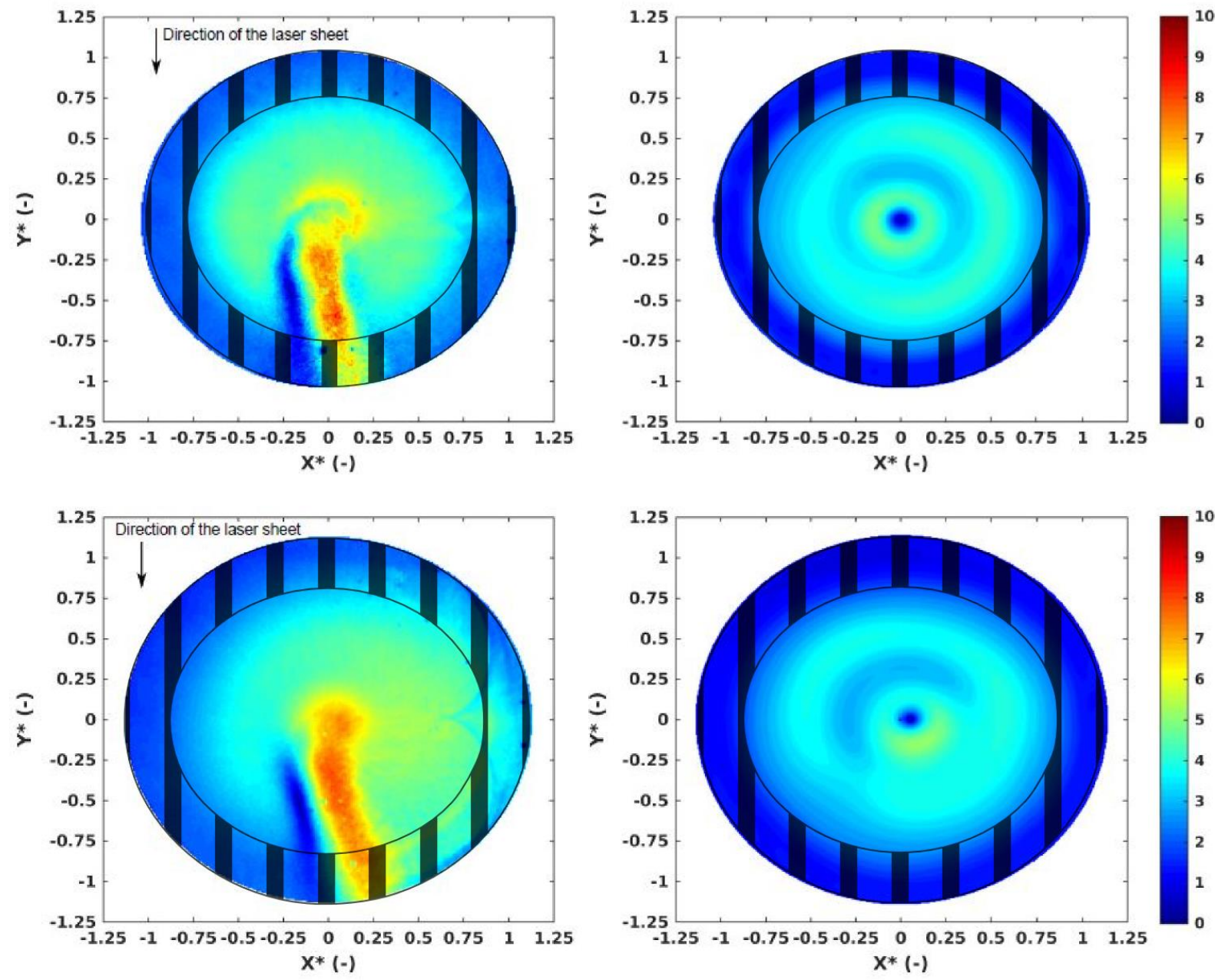

Figure 6: $\sqrt{C_{u}^{2}+C_{r}^{2}} \mathrm{~m} \mathrm{~s}^{-1}$. Experimental measurements (left) and U-RANS CFD results (right). Horizontal sections S1 (top) and S2 (bottom). OP2. 

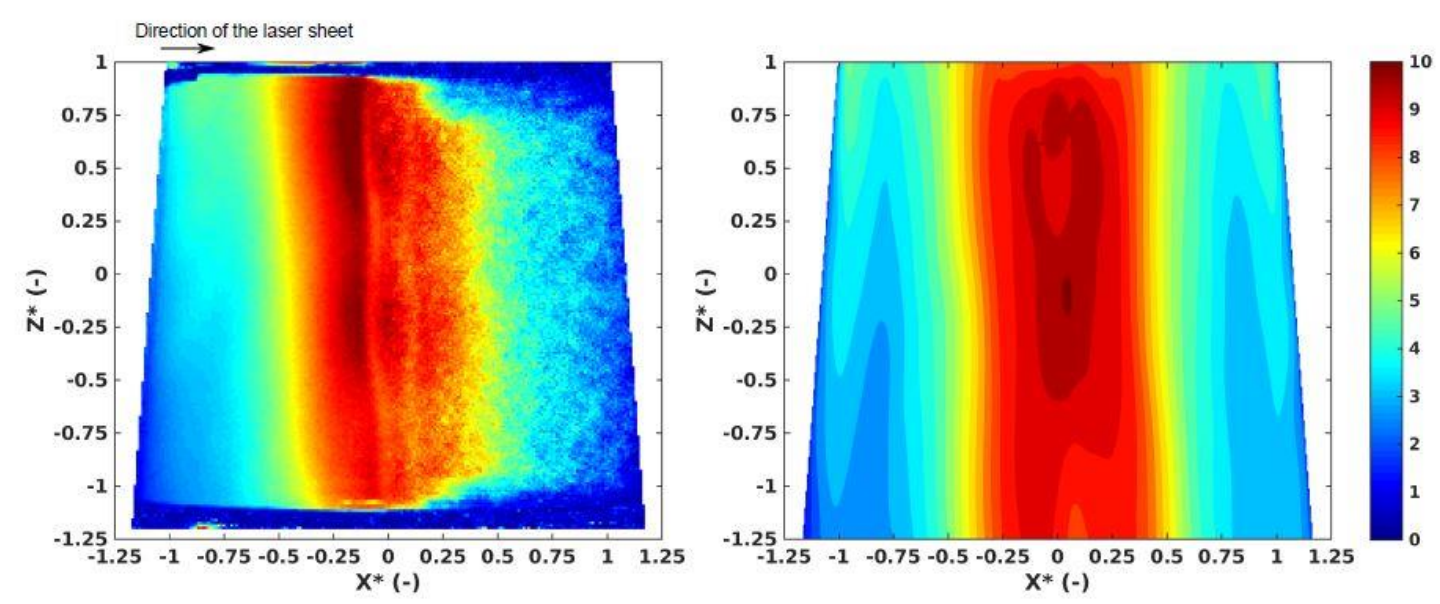

Figure 7: $\sqrt{C_{z}^{2}+C_{r}^{2}} \mathrm{~m} \mathrm{~s}^{-1}$. Experimental measurements (left) and U-RANS CFD results (right). Vertical section. OP2.

\section{INVESTIGATION OF THE TRANSITION}

The transition between a stable and an unstable flow configuration is investigated by using the numerical results validated with the experimental data.

The difference between the stable and the unstable vortex rope is clearly visible by computing the local pressure coefficient $C_{p}$ defined by (9) in the section 1 of the draft tube (see

Figure 8).

$$
C_{p}=\frac{p-\bar{p}}{0.5 \rho U_{\overline{1} e}^{2}}
$$

Both experimentally and numerically, the local pressure coefficient is close to zero for the two highest $\sigma$ values corresponding to OP1 and OP2 and shows strong fluctuations for the lowest $\sigma$ value corresponding to OP3. For OP3, despite the fact that only one cycle of the vortex rope collapse is captured by the computation, it is noticeable that the calculated period and amplitude of the pressure coefficient match the ones obtained experimentally. The peaks of the pressure coefficient observed in the experiment at OP3 are related to the periodic collapse of the vortex rope accompanied by the bubble shedding from the runner (see

Figure 5). The computation crashes after the vortex rope collapse due to the inability of the solver to deal with strong pressure waves. Nevertheless, since the pressure signal predict by the simulation is in accordance with the experimental signal regarding both the amplitude and the period, the CFD results are used to analyze the flow at the unstable operating condition. The remaining analysis of the transition from a stable to an unstable flow will focus on OP2 and OP3, since OP1 and OP2 are both stable operating points.
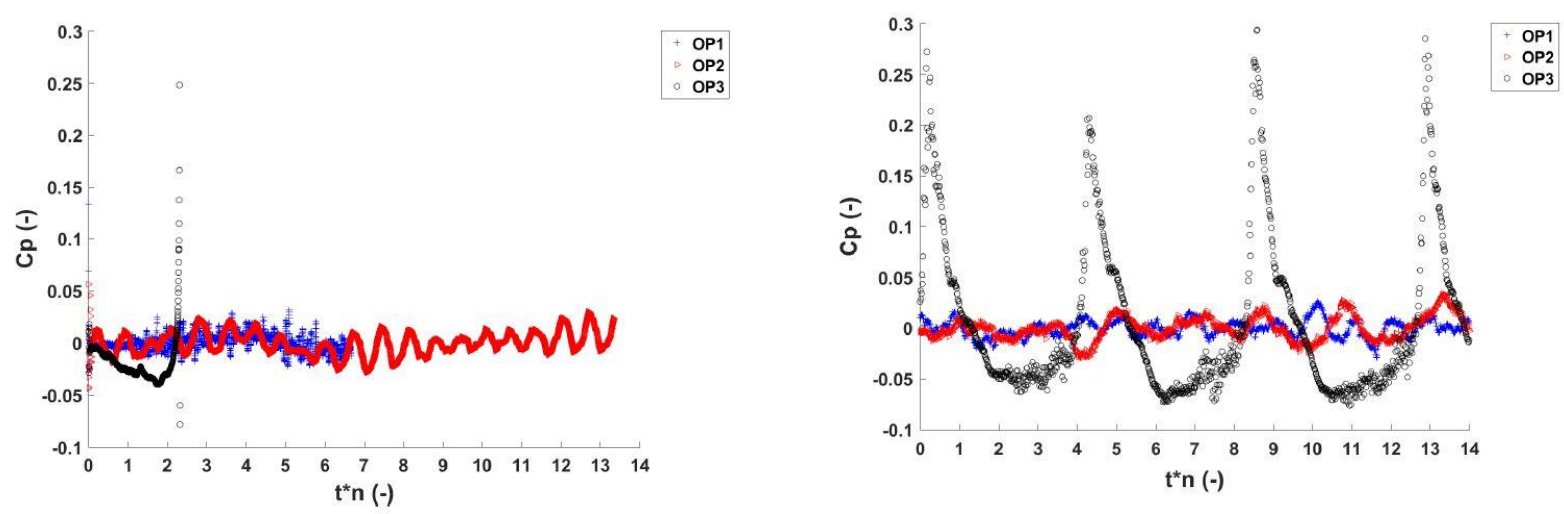

Figure 8: Time history of the local pressure coefficient $\mathrm{C}_{\mathrm{p}}$ in section $\mathrm{S} 1$ of the draft tube. U-RANS CFD results (left) and experimental measurements (right). 
The iso-surface of the liquid volume fraction $\alpha_{L}=0.9$ in the runner and draft tube domains is displayed in Figure 9. In both cases, the vortex rope is observed in the draft tube cone. At OP2, only a small amount of vapor is present at the trailing edge of the runner blades, whereas at OP3, cavitation sheets extend over a large part of the blade suction sides, which is also observed experimentally at OP3 [4,19]. This modification of the cavitation pattern leads to a modification of the flow topology downstream the runner. The modification of the flow pattern can be illustrated by computing the swirl number $S$ [20] defined by (10) in the section 1 of the draft tube (see Figure 10).

$$
S=\frac{2 \pi \int_{0}^{R} \rho r^{2} C_{u} C_{z} d r}{2 \pi R_{1} \int_{0}^{R} \rho r C_{z}^{2} d r}
$$

At OP3, compared to the two other operating points, the swirl number decreases by approximately $40 \%$ mainly due to a decrease of the axial flux of angular momentum. The value of the swirl number at OP 3 is close to the value measured experimentally [4], which is in the range between 0.2 and 0.3 .

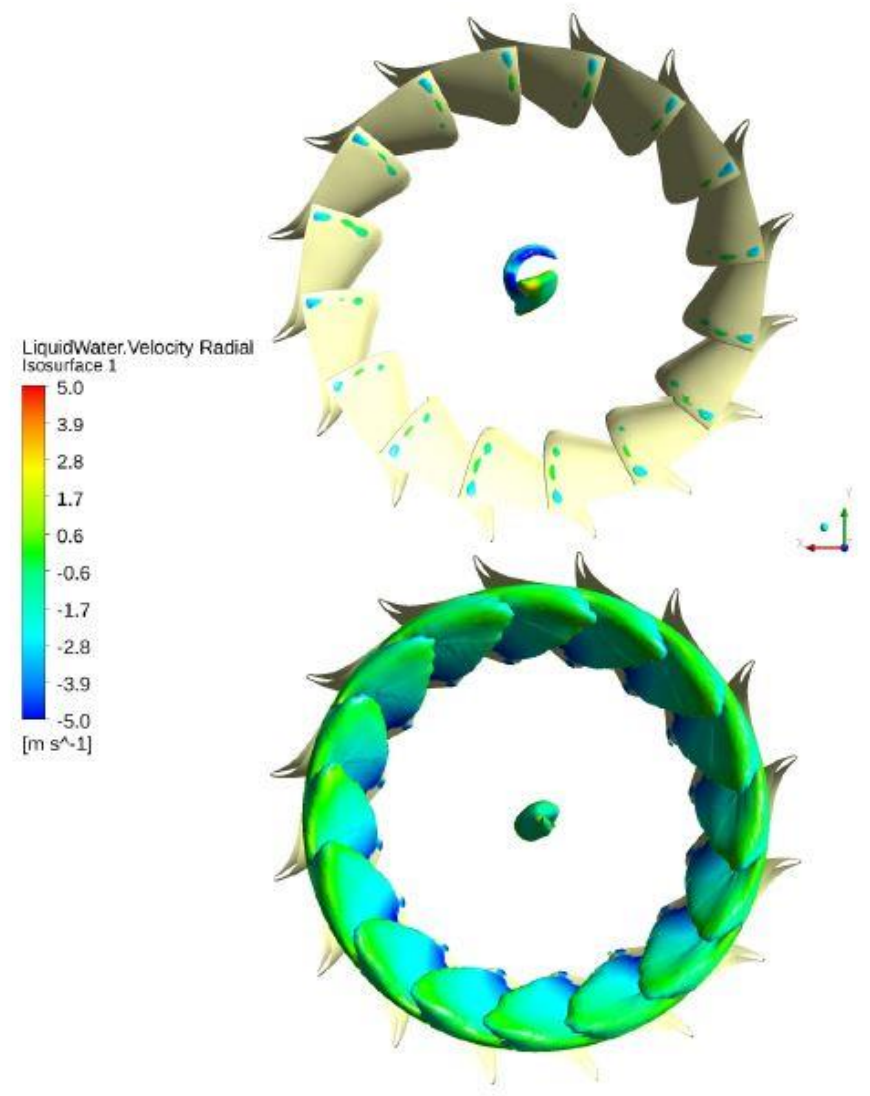

Figure 9: Instantaneous iso-surface of the liquid volume fraction $\alpha_{L}=0.9$ colored by the radial velocity $C_{r}$. OP2 (top) and OP3 at $t^{*} n=2.14$ (bottom). U-RANS CFD results. 


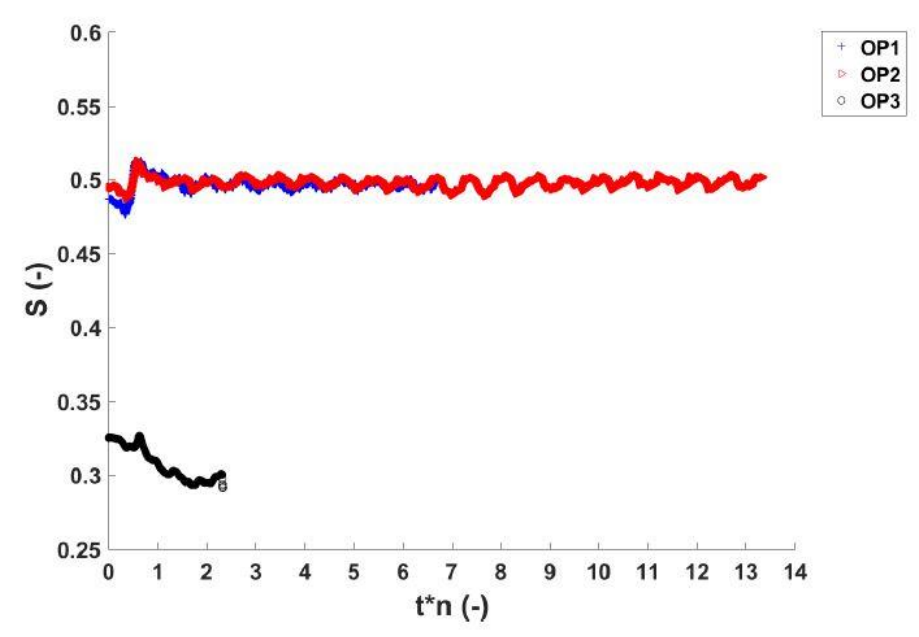

Figure 10: Swirl number in section $S 1$ of the draft tube. U-RANS CFD results.

From the previous description of the flow pattern, a hypothetical scenario to explain the development of an unstable vortex rope would be:

- The diminution of the $\sigma$ number of the machine leads to the formation of cavitation sheets at the trailing edges of the runner blades and a growth of the volume of the cavitating vortex rope.

- The runner outlet flow pattern is modified compared to a stable vortex rope, leading to local flow instabilities.

- When the instabilities reach a certain intensity level to be determined, the cavitation structures collapses.

- A new cycle begins, with the redevelopment of the flow swirl and thus the vortex rope, as described in [4].

\section{CONCLUSION}

URANS simulations are carried out to compute the cavitating vortex rope that develops in the draft tube of a Francis turbine at full load for three different cavitation numbers. Two stable operating points and an unstable operating point are considered. CFD results are first compared with experimental data to assess the validity of the numerical approach. For the two stable operating points, a good agreement is observed between the simulations and the experiments with a difference lower than $2 \%$ regarding the turbine performances, moreover a similar flow pattern is observed in the cone of the draft tube. For the unstable operating point, the simulation captures only one cycle of the vortex rope oscillation before stopping when the first collapse of the vortex rope occurs. The inability of the simulation to go beyond the collapse is related to the inability of the solver to deal with strong pressure fluctuations. However, the cycle computed seems to agree with the experiment as shown by the time monitoring of the pressure coefficient in the draft tube. Therefore, the simulation is used to formulate a hypothetical scenario that explains the transition from a stable to an unstable cavitating vortex rope. The transition seems to occur when cavitation sheets develop at the trailing edges of the runner blades. The development of these cavitation sheets modifies strongly the flow pattern downstream the runner as revealed by the diminution of the swirl number. The flow becomes unstable leading finally to the collapse of the cavitating vortex rope.

This scenario has to be confirmed since the simulation is not robust enough yet to capture several cycles of the vortex rope collapse and under-estimates the volume of the cavitating vortex rope.

\section{NOMENCLATURE}

$\begin{array}{lll}\mathrm{C}_{\mathrm{p}} & - & \text { Pressure coefficient } \\ \vec{C} & \mathrm{~m} \mathrm{~s}^{-1} & \text { Velocity vector } \\ \mathrm{C}_{\mathrm{z}} & \mathrm{m} \mathrm{s}^{-1} & \text { Axial velocity component } \\ \mathrm{C}_{\mathrm{u}} & \mathrm{m} \mathrm{s}^{-1} & \text { Circonferential velocity component }\end{array}$




\begin{tabular}{|c|c|c|}
\hline$\overline{\mathrm{C}_{\mathrm{r}}}$ & $\mathrm{m} \mathrm{s}^{-1}$ & Radial velocity component \\
\hline $\mathrm{D}$ & $\mathrm{m}$ & Runner diameter \\
\hline $\mathrm{E}$ & $\mathrm{J} \mathrm{kg}^{-1}$ & Specific hydraulic energy \\
\hline $\mathrm{k}$ & $\mathrm{m}^{2} \mathrm{~s}^{-2}$ & Turbulent kinetic energy \\
\hline $\mathrm{n}$ & $\mathrm{s}^{-1}$ & Runner rotating frequency \\
\hline$n_{E D}=\frac{n D}{F^{0.5}}$ & - & Speed factor \\
\hline NPSE & - & Net Positive Suction Head [12] \\
\hline $\mathrm{p}$ & $\mathrm{Pa}$ & Pressure \\
\hline $\bar{p}$ & $\mathrm{~Pa}$ & Spatially averaged pressure in a specfic section \\
\hline $\mathrm{p}_{\mathrm{v}}$ & $\mathrm{Pa}$ & Saturated vapor pressure \\
\hline & $\mathrm{m}^{3} \mathrm{~s}^{-1}$ & Flow discharge \\
\hline$Q_{E D}=\frac{Q}{D^{2} E^{0.5}}$ & - & Discharge factor \\
\hline $\mathrm{R}$ & $\mathrm{m}$ & Radius \\
\hline$R_{\overline{1}}$ & $\mathrm{~m}$ & Runner radius at the runner outlet \\
\hline$r_{g}$ & - & Gas volume fraction \\
\hline $\mathrm{r}_{\text {nuc }}$ & - & Volume fraction of the nucleation sites \\
\hline $\mathrm{R}_{\text {nuc }}$ & $\mathrm{m}$ & Radius of the nucleation sites \\
\hline $\mathrm{S}$ & - & Swirl number \\
\hline & $\mathrm{N} \mathrm{m}$ & Torque \\
\hline$T_{E D}=\frac{I}{\rho D^{3} E}$ & - & Torque factor \\
\hline$U_{\bar{I}}$ & $\mathrm{~m} \mathrm{~s}^{-1}$ & Rotating velocity at the outer diameter at the runner outlet \\
\hline$\alpha_{\mathrm{L}}$ & - & Liquid volume fraction \\
\hline$\mu$ & $\mathrm{kg} \mathrm{m}^{-1} \mathrm{~s}^{-1}$ & Molecular dynamic viscosity \\
\hline$\mu_{\mathrm{t}}$ & $\mathrm{kg} \mathrm{m}^{-1} \mathrm{~s}^{-1}$ & Turbulent dynamic viscosity \\
\hline$v$ & - & Specific speed \\
\hline$\rho$ & $\mathrm{kg} \mathrm{m}^{-3}$ & Density \\
\hline$\rho_{\mathrm{g}}$ & $\mathrm{kg} \mathrm{m}^{-3}$ & Gas density \\
\hline & $\mathrm{kg} \mathrm{m}^{-3}$ & Liquid density \\
\hline$\sigma=\frac{N P S E}{E}$ & - & Thoma number \\
\hline$\sigma_{\mathrm{u}}$ & - & Cavitation number based on the runner peripheral velocity \\
\hline$\omega$ & $\mathrm{rad} \mathrm{s}^{-1}$ & Runner rotating speed \\
\hline$\overline{\bar{\tau}}$ & $\mathrm{kg} \mathrm{m}^{-1} \mathrm{~s}^{-2}$ & Viscous stresses \\
\hline$\overline{\overline{\tau_{t}}}$ & $\mathrm{~kg} \mathrm{~m}^{-1} \mathrm{~s}^{-2}$ & Turbulent stresses \\
\hline
\end{tabular}

\section{ACKNOWLEDGEMENTS}

The research leading to the results published in this paper is part of the HYPERBOLE research project, granted by the European Commission (ERC/FP7-ENERGY-2013-1-Grant 608532).

\section{REFERENCES}

[1] Favrel, A., Müller, A., Landry, C., Yamamoto, K., \& Avellan, F. (2015). Study of the vortex-induced pressure excitation source in a Francis turbine draft tube by particle image velocimetry. Exp. in Fluids, $56(12), 215$.

[2] Favrel, A., Müller, A., Landry, C., Yamamoto, K., \& Avellan, F. (2016). LDV survey of cavitation and resonance effect on the precessing vortex rope dynamics in the draft tube of Francis turbines. Exp. in Fluids, 57 (11), 168. 
[3] Koutnik, J., Nicolet, C., Schohl G., \& Avellan, F. (2006). Over-load Surge Event in a Pumped-Storage Power Plant. In 23rd IAHR Symp. on Hydraulic Machinery and Systems, 1, 1-15.

[4] Müller, A., Favrel, A., Landry, C. \& Avellan F. (2017). Fluid-structure interaction mechanisms leading to dangerous power swings in Francis turbines at full load. J. of Fluids and Structures, 69, 56-71.

[5] Panov, L.V, Chirkov, D.V., Cherny, S.G., Pylev, I.M. \& Sotnikov, A.A. (2012). Numerical simulation of steady cavitating flow of viscous fluid in a Francis hydroturbine. Thermophysics and Aeromechanics, 19 (3):415-427.

[6] Dörfler, P.K., Keller, M., \& Braun, O.(2010). Francis full load surge mechanism identified by unsteady 2-phase CFD. IOP Conf. Series: Earth and Environmental Science, 12 (1), 012026.

[7] Flemming, F., Foust, J., Koutnik, J. \& Richard, K. F. (2009). Overload Surge Investigation Using CFD Data. Int. J. of Fluid Machinery and Systems, 2 (4), 315-323.

[8] Mössinger, P., Conrad, P., \& Jung, A. (2014). Transient two-phase CFD simulation of overload pressure pulsation in a prototype sized Francis turbine considering the waterway dynamics. In IOP Conf. Series: Earth and Environmental Science, 22, 032033.

[9] Chirkov, D., Panov, L., Cherny, S., \& Pylev, I (2014). Numerical simulation of full load surge in Francis turbines based on three-dimensional cavitating flow model. In IOP Conf. Series: Earth and Environmental Science, 22, 032036.

[10] Panov, L.V, Chirkov, D.V., Cherny, S.G., \& Pylev, I.M. (2014). Numerical simulation of pulsation processes in hydraulic turbine based on 3D model of cavitating flow. Thermophysics and Aeromechanics, 21 (1), 31-43.

[11] Alligné, S., Decaix, J., Müller, A., Nicolet, C., Avellan, F., \& Münch, C. (2016). RANS computations for identification of 1-D cavitation model parameters: application to full load cavitation vortex rope. In IOP Conf. Series: Earth and Environmental Science, 49, 082014.

[12] IEC standards (1999). 60193: Hydraulic Turbines, Storage Pumps and Pump-Turbines - Model Acceptance Tests, Int. Electrotechnic Commission, second edn.

[13] Brennen, C.E (1995). Cavitation and bubble dynamics. Oxford University Press, New York.

[14] Menter, F.R. (1993). Zonal two equation k- $\omega$ turbulence models for aerodynamic flows. In AIAA 932906, $24^{\text {th }}$ Fluid Dynamics Conference.

[15] Zwart, P., Gerber, A., \& Belamri, T. (2004). A two-phase flow model for predicting cavitation dynamics. In Fifth Int. Conf. on Multiphase Flow, 152.

[16] Plesset, M. S. (1949). The dynamics of cavitation bubbles. J. of Applied Mechanics, 16, 277-282.

[17] Bakir, F., Rey, R., Gerber, A.G., Belamri, T., \& Hutchinson B. (2004). Numerical and Experimental Investigations of the Cavitating Behavior of an Inducer. The Int. J. of Rotating Machinery, 10 (1), 1525 .

[18] Wack, J., \& Riedelbauch, S. (2015). Numerical simulations of the cavitation phenomena in a Francis turbine at deep part load conditions. J. of Physics: Conf. Series, 656, 012074.

[19] Müller, A., Favrel, A., Landry, C., Yamamoto, K. \& Avellan F. (2014). On the physical mechanisms governing self-excited pressure surge in Francis turbines. In IOP Conf. Series: Earth and Environmental Science, 22, 032034.

[20]Gupta, A.K., Lilley, D.G., \& Syred, S. (1984). Swirl Flows. Abacus Press, Tunbridge Wells, Kent, England. 